\title{
Effects of Different Anti-Stressors on Growth, Serum Chemistry and Meat Quality Attributes of Japanese Quail
}

\section{-Author(s)}

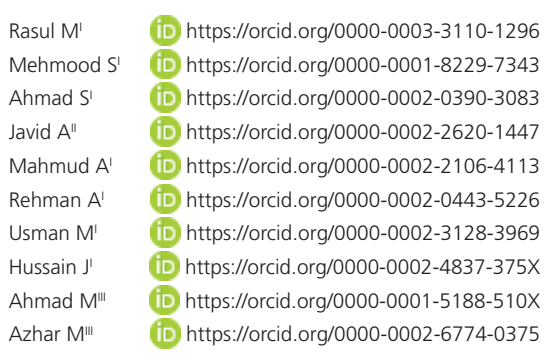

Department of Poultry Production, Faculty of Animal Production \& Technology

Deparment of Wildlife and Ecology, Faculty of Fisheries and Wildlife, University of Veterinary and Animal Sciences, Lahore, 54000, Pakistan

III Poultry Research Institute, Rawalpindi, 46000, Pakistan

\section{ABSTRACT}

The aim of the present study was to evaluate the effect of different anti-stressors on growth performance, carcass traits, bloodchemistry and meat quality attributes of broiler Japanese quail. For this purpose, a total of 1,875 quail chicks were procured and arranged according to completely randomized design, birds were divided into 5 treatment groups having 5 replicates of 75 birds each. The treatments consisted of four anti-stressors i.e., synthetic anti-stressors (Vitamin C and Betaine) and natural anti-stressors (Turmeric and Chia Seed) along with a control group. Bird's diets were supplemented with vitamin $C$, betaine, turmeric and chia seed @ 600 mg/kg, 700 mg / kg, 300 mg/kg and 7,000 mg/kg respectively. After four weeks, 10 birds per treatment were slaughtered (Halal method), de-feathered, eviscerated and their carcass traits, serum chemistry and meat quality attributes were calculated. Birds supplemented with betaine revealed significantly $(p \leq 0.05)$ lower feed intake, glucose, cholesterol, $\mathrm{H}: \mathrm{L}$ ratio, better weight gain, times of gain, FCR and highest anti-oxidant assay and total viable count. However, carcass traits, processing traits and blood cortisol level did not differ ( $p>0.05$ ) among the treatment groups. In conclusion, addition of antistressors (especially betaine) in the diet of growing Japanese quail had positive influence on growth and serum chemistry.

\section{INTRODUCTION}

Japanese quail (Coturnix japonica) were initially domesticated as pet song birds or as game birds then with time they were converted into valuable meat type birds (Kayang et al., 2004). Japanese quail is a domestic bird of economic importance for commercial meat production and lay unique flavor eggs (Mahmoud El-Tarabany, 2016). Japanese quail are the best meat producers among all the quails present in the world with an average adult live weight at four weeks of age of 200 grams (Ahmad, 2016). Japanese quails are excellent laboratory animals used for research purposes as they have low maintenance cost, short generation interval (3-4 generation per year), hardy, resist disease, high egg production and require lower space and equipment utility (Minvielle, 2004). Role of environment cannot be denied as commercial and intensive poultry production is associated with various stresses leading to the decrease of productive and reproductive performance of growing chickens, parent birds, and layers (Surai \& Fisinin, 2016). Japanese quails are also affected by various environmental and management stresses that affect their productivity during humid hot season (Bello \& Sulaiman, 2016).

Pakistan is located in geographical regions of southwestern Asia and situated in both northern and eastern hemisphere, where, July and August are considered to be humid hot months (Daghir, 2009). During these months the birds experience a series of stresses, among these 
Rasul M, Mehmod S, Ahmad S, Javid A, Mahmud A, Rehman A, Usman M, Hussain J, Ahmad M, Azhar M
Effects of Different Anti-Stressors on Growth, Serum Chemistry and Meat Quality Attributes of Japanese Quail heat stress has been identified as a major problem affecting performance and physiological attributes of chickens (Daghir, 2008). Heat stress is the major cause of declining poultry farming in open sided houses, resulting into emptying 25,000 open sided houses (Akram, 2013) along with decreased performance of laying quail in tropical and subtropical countries (Mahmoud El-Tarabany, 2016). There are different management strategies to counter these stresses i.e., use of high speed cool air to remove bird heat through convection and early age feed restriction to alleviate heat stress (Zulkifli et al., 2000). The vitagene concept of fighting stresses emerged as a new direction in a nutritional research. The vitagenes are responsible for preserving cellular homeostasis in stressful conditions by additional synthesis of heat shock proteins in the body (Surai \& Fisinin, 2016). There are also different nutritional strategies being adopted to reduce heat stress in chicken (Sahin et al., 2009). The use of different additives such as ammonium chloride (Smith \& Teeter, 1993), Potassium Chloride (El-Deek et al., 2009), Sodium bicarbonate (Hayat et al., 1999), probiotics (Lin et al., 2006), garlic (Adibmoradi et al., 2006), mint (Gill et al., 2002) and yogurt (Zulkifli et al., 2000) are helpful in reducing the deleterious effect of high heat index in broilers. The different anti-stressors in feed like vitamin C (Whitehead \& Keller, 2003), betaine (Attia et al., 2005), turmeric (Hosseini et al., 2012) and chia seed (Uribe et al., 2011) showed beneficial responses in reducing the effect of heat stress on birds. Betaine has osmoregulatory properties that reduces negative effect of heat stress on growth performance and enhances survival of poultry by improving cell osmoregulation (Borges et al., 2007). Broilers reared under the supplementation of betaine showed an improvement in growth, feed conversion ratio (FCR) and immune response (Wang et al., 2004). Vitamin C decreases the synthesis and secretion of corticosteroids and alleviates the negative effects of heat stress on bird (Kulkani et al., 2012). The use of vitamin $C$ as an anti-stressor in heat stressed broiler resulted into an increased performance and better carcass quality (Sahin \& Kucuk, 2001). Similarly, Chia seed (Salvia hispanica) can also be used as an anti-stressor because it is potentially a great source of antioxidants which protect the bird from heat stress and result in better health condition (Uribe et al., 2011). Turmeric is a natural polyphenol that exhibits antioxidant property and alleviates oxidative stress in heat stressed Japanese quails (Sahin et al., 2012). It is also found beneficial in reducing the negative effect of heat stress on broiler's growth performance, production performance and immune system (Hosseini et al., 2012). Despite mushrooming environment-controlled poultry houses throughout the world, temperature and humidity are still core issues in hot and humid areas especially in Pakistan. During this season, particularly in July-August, poultry experience a series of stresses; among these, heat stress is more vigorous and can be eliminated through some feed manipulations. Use of anti-stressor like betaine, vitamin C, $\mathrm{KCl}$, and Chia seed in poultry feeds effectively reduce heat stress. The present study was planned to find out the effect of different anti-stressors on growth performance, carcass traits, blood chemistry and meat quality attributes of broiler Japanese quail.

\section{MATERIALS AND METHODS}

The present study was conducted at the Avian Research and Training Centre (ARTC), University of Veterinary and Animal Science, Lahore, Pakistan. A total of 1,875 quail chicks were procured from ARTC hatchery and were arranged in a completely randomized design, birds were divided into 5 treatment groups having 5 replicates of 75 birds each. The treatments consisted of four anti-stressors i.e., synthetic anti-stressors (Vitamin $C$ and Betaine) and natural anti-stressors (Turmeric and Chia Seed) along with a control group. The bird's diets were supplemented with vitamin $\mathrm{C}$, betaine, turmeric and chia seed @ 600 mg $/ \mathrm{kg}, 700$ mg $/ \mathrm{kg}, 300$ mg $/ \mathrm{kg}$ and $7,000 \mathrm{mg} / \mathrm{kg}$, respectively for the duration of four weeks. The study was according to the guidelines and code of practices of UVAS, Lahore, Pakistan and ethical approval was also granted.

\section{Housing and Management}

The birds were maintained in an octagonal quail shed having a French made 5-tiered battery cage system specially designed for meat type quails [83.61 $\mathrm{cm}^{2} /$ quail during brooding (14 days) and $150 \mathrm{~cm}^{2} /$ quail during growing (28 days)]. The birds were provided with ad libitum feed (Table 1), provision of fresh and clean water was ensured by nipple drinker system. The birds were reared under the humid hot season of august and fed on a diet formulated by the following ingredients supplemented with different anti-stressors. The effect of these anti-stressors was observed on growth performance, carcass traits, serum chemistry and meat quality attributes of Japanese quail. After four weeks, 10 birds per treatment were slaughtered (Halal method; Shahdan et al., 2016) and blood was collected for the determination of blood chemistry. After slaughtering, the birds were de-feathered, eviscerated and their carcass traits and meat quality attributes were calculated. 
Rasul M, Mehmod S, Ahmad S, Javid A, Mahmud A, Rehman A, Usman M, Hussain J, Ahmad M, Azhar M
Effects of Different Anti-Stressors on Growth, Serum Chemistry and Meat Quality Attributes of Japanese Quail

\section{Parameter Studied}

Data were recorded regarding growth performance (feed intake, body weight, body weight gain, time of gain, FCR and livability) for the duration of four weeks.

\section{Blood chemistry and Carcass traits}

At the end of the $4^{\text {th }}$ week, ten birds were randomly picked up from each treatment and $2 \mathrm{ml}$ of blood was collected in marked test tubes from Jugular vein of each bird during slaughtering (Halal method). Serum samples were extracted by centrifugation and stored at $-20^{\circ} \mathrm{C}$ for measuring blood glucose, cholesterol and cortisol. Blood (2 $\mathrm{ml} /$ bird) was collected in EDTA containing tubes and blood smear was prepared by using Grunwald-Giemsa stain, and the number of $\mathrm{H}$ and $\mathrm{L}$ was counted to a total of 100 cells by the method adopted by Gross \& Siegel (1983). Carcass traits were recorded regarding live weight, dressed weight, dressing \%, liver, gizzard and heart weight and expressed as percentage of body weight.

\section{Sensory evaluation and processing traits}

After rearing Japanese quail, Sensory panel test was performed on breast samples by roasting the sample without salt and spice (Castellini et al., 2002). The cooked samples were immediately sliced into pieces and were offered to panelists. For each sensory characteristic, participants were instructed to score the intensity of evaluation on a nine point's hedonic scale for (color, flavor, juiciness, tenderness, oiliness and overall acceptability).

The breast sample was collected, and color measurement was taken at 01-hour post slaughtering. The breast samples packed in trays were placed at chilling temperature. The color was measured using Minolta CR-410 colorimeter, after its calibration using standard white tile CR-A44 at $1^{*}=94.93, a^{*}=-0.13$ and $b^{*}=2.55$. The $\mathrm{pH}$ of the breast meat was measured using $\mathrm{pH}$ meter with meat penetrating probe (WTW, pH 3210 SET 2, Germany) from three places of breast. The $\mathrm{pH}$ was recorded on 24 hours after slaughtering while keeping carcass in chiller.

\section{Anti-oxidant assay and intestinal viable count}

At the end of 4 weeks, total fat content of meat was determined by ether extraction method and meat anti-oxidant assay as total phenolic content, total flavonoid content, total anti-oxidant capacity was determined by spectrophotometry method as described by Khanahmadi (2010), Nile, Khobragade
(2010) and Nabasree \& Bratati (2007), respectively. At the end of the $4^{\text {th }}$ week, ten birds were randomly picked up from each treatment and Intestinal viable count was counted by viable counting method (AOAC, 1990).

\section{Statistical Analysis}

Data were analyzed through one-way ANOVA technique (Steel et al., 1997) using PROC GLM in SAS software. Treatment means were compared through Duncan's (1955) Multiple Range test assuming following mathematical model:

$$
\begin{aligned}
Y_{i j} & =\mu+\tau_{i}+\varepsilon_{i j} \\
& \text { Whereas, } \\
Y_{i j}= & \text { Observation of dependent variable recorded on } \\
& i^{\text {th }} \text { treatment } \\
\mu= & \text { Population Mean } \\
\tau_{i}= & \text { Effect of } i^{\text {th }} \text { treatment }(i=1,2,3,4,5) \\
\varepsilon_{i j}= & \text { Residual effect of } j^{\text {th }} \text { observation on } i^{\text {th }} \text { treatment } \\
& \text { NID } \sim 0, \sigma^{2}
\end{aligned}
$$

\section{RESULTS AND DISCUSSION}

\section{Growth Performance}

In this study, the birds having vitamin $\mathrm{C}$ in their diet showed the highest feed intake ( $\mathrm{Fl})$ as compared to the birds supplemented with other anti-stressors and the control group. Vitamin $C$ is known to increase the use of corticosteroids and reduce the synthesis of corticosteroid hormones released during stress in birds. By decreasing synthesis and secretion of corticosteroids, vitamin $C$ alleviates the negative effects of stress and increases feed intake (Kutlu \& Forbes, 1993). Similar findings were also reported in the study of heat stressed Japanese quail, the vitamin C supplementation significantly increases Fl (Sahin et al., 2003). Similarly, improvement in $\mathrm{Fl}$ of 21 day-old unsexed slow growing broilers were also reported when fed different levels of dietary betaine (Attia et al., 2009). Moreover, the turmeric supplementation in the diet of heat stressed Japanese quail significantly increases cumulative $\mathrm{FI}$ when compare to the control treatment (Sahin et al., 2012). However, contradictory studies also reported that supplementation of turmeric in feed of Japanese quail do not affect daily FI (Saraswati et al., 2013). Similarly, turmeric supplementation did not affect Fl in heat stressed broilers (Hosseini et al., 2012).

In the present study, maximum body weight gain (BWG) was observed in birds fed with betaine and vitamin $C$ in their diet as compared to the birds 
Rasul M, Mehmod S, Ahmad S, Javid A, Mahmud A, Rehman A, Usman M, Hussain J, Ahmad M, Azhar M
Effects of Different Anti-Stressors on Growth, Serum Chemistry and Meat Quality Attributes of Japanese Quail supplemented with chia seed, turmeric and the control group, respectively. The important function that betaine performs is the active donation of a methyl group that maintains the cellular water homeostasis (Kidd et al., 1997). It takes part in the synthesis of protein and could be helpful in weight gain of broilers (Rima, 2013). The evidences regarding the use of betaine in heat stress condition proves that it is an important nutrient due to its multiple functions (Eissen \& Enting, 2007). The findings of the present study are in accordance with the study of broilers who found that dietary supplementation of betaine improve weight gain in high temperatures (Chen \& Chiang, 2002). Similarly, improvement in BWG of 21 day-old unsexed slow growing broilers were also reported when fed different levels of dietary betaine (Attia et al., 2009). However, other study found that betaine supplementation increases BWG in one-day old unsexed chicks of El-salam strain during the first 4 weeks but did not show any effect during 5-8 week of age when fed medium and high levels of betaine (Hassan et al., 2005). Moreover, the dietary supplementation of chia seed causes significant decrease in BWG of broilers when compared to the controls (Ayerza et al., 2002). Similarly, no significant differences in BWG of broilers were observed when compared with low or high level of chia seed supplementation (Ayerza et al., 2002). Another study reported that supplementation of turmeric in Japanese quail did not affect BWG (Saraswati et al., 2013).

In the present experiment, the Japanese quail supplemented with betaine showed better feed conversion ratio (FCR) as compared to the birds supplemented with other anti-stressors and the control group. This might be attributed with the highest body weight of birds in this group due to improved feed consumption that give better feed to weight ratio. The findings of the study are in line with the study of heat stressed broiler who found that FCR improved significantly with the highest amount of betaine (Enting \& Eissen, 2007). In the study of 21 day-old unsexed slow growing broilers, betaine showed improvement in FCR when fed different levels of dietary betaine (Attia et al., 2009). Another study reported that betaine supplementation improves FCR in broilers during the first 4 weeks but did not show any affect during 5-8 week of age when fed medium and high levels of betaine (Hassan et al., 2005). However, a contradictory study reported that the dietary supplementation of chia seed causes poor FCR in broilers when compared to the controls (Ayerza et al., 2002). Similarly, no significant differences FCR of broilers were observed when compare with low or high level of chia seed supplementation (Ayerza et al., 2002). Supplementation of turmeric in heat stress broilers did not affect FCR (Hosseini et al., 2012).

The present study observed no difference regarding livability \% of birds supplemented with different anti-stressors. The findings of the present study are confirmed by other studies that reported that Betaine is beneficial in reducing the negative effect of heat stress and in enhancing survival of poultry by improving cell osmoregulation (Graham, 2002). Betaine supplementation increases the livability in heat stressed broilers (Khattak et al., 2012). The heat stressed broilers supplemented with betaine in their diet decreases the mortality rate (Khattak et al., 2012). The dietary supplementation of chia has no effect on mortality rate in birds when compared to the controls (Ayerza etal., 2002). A contradictory study also reported that vitamin $C$ supplementation causes no significant differences in terms of mortality rate in the period from 0 to 3 weeks of age in heat stressed broilers. However, significant differences were observed in the periods from 4 to 6 weeks of age (Toplu et al., 2014).

\section{Carcass traits}

The present experiment did not find any difference regarding live body weight (LBW) of Japanese quail supplemented with different anti-stressors. The results of this study are in line with the study on heat stressed Japanese quail which reported that vitamin $C$ supplementation has no significant difference in LBW at slaughter when compared to the control in heat stressed Japanese quail (Mehmet et al., 2005). Contrarily, other studies found that vitamin C supplementation resulted in higher LBW at slaughter in heat stressed Japanese quail (Sahin \& Kucuk, 2001).

The dressed weight (DW) of Japanese quail reared under different anti-stressors recorded no significant difference. Similar findings also reported that vitamin C supplementation had no significant effect on DW of heat stressed Japanese quail when compared to the control (Imik et al., 2010). However, other studies noted that the vitamin $C$ supplementation resulted increase in cold DW in heat stressed Japanese quail (Kulkani et al., 2012).

This experiment recorded no difference regarding dressing \% of birds fed with different anti-stressors. Similar findings also showed that the vitamin $C$ supplementation had no effect on carcass yield when compare with control in heat stressed Japanese quail (Mehmet et al., 2005). The addition of betaine did 
Rasul M, Mehmod S, Ahmad S, Javid A, Mahmud A, Rehman A, Usman M, Hussain J, Ahmad M, Azhar M
Effects of Different Anti-Stressors on Growth, Serum Chemistry and Meat Quality Attributes of Japanese Quail not affect carcass percentage in heat stressed broilers (Enting \& Eissen, 2007). Contradictory studies also reported that in slow growing broilers, better dressing percentage was observed when the birds were fed different levels of dietary betaine (Attia et al., 2009). The vitamin $C$ supplementation resulted in the increase in cold carcass yield in heat stressed Japanese quail (Sahin \& Kucuk, 2001).

The results of the present study did not reveal any difference regarding gizzard, liver, heart, shank (SW) and head weight (HW) \% of Japanese quail reared under different anti-stressors. Similarly, other studies found no significant influence of dietary betaine on giblets in slow growing chicks (Hassan et al., 2005). However, it was also reported that betaine addition to the diets of broilers reared under acute heat stress improved the giblets percentage especially liver and heart weight \% (Attia et al., 2009).

\section{Blood chemistry}

Betaine and chia seed supplemented birds showed lower blood glucose and cholesterol level as compared to the control group. This might be attributed to the fact that the production of glucose is directly proportional to the release of glucocorticoid hormone which is being produced under heat stress conditions through gluconeogenesis. Betaine (non-protein amino acid) as an osmoregulatory agent for relief the adverse effect of heat stress and reduces the breakdown of body lipids in heat stress condition and lowers blood glucose and cholesterol (Borges et al., 2007). The results of the present study are in accordance with other studies that found betaine supplementation in heat stressed slow growing broilers to improve the physiological parameters by reducing serum glucose levels (Attia et al., 2009). The vitamin $C$ supplementation may result into significant decrease in serum cholesterol in heat stressed Japanese quail (Sahin et al., 2004). Moreover, turmeric supplementation before sexual maturity (first 30 days) increases serum glucose while turmeric supplementation at 7-8 month of Japanese quail decreases serum glucose (Saraswati et al., 2013).

In this study, no significant difference was reported regarding blood cortisol levels of Japanese quail reared under different anti-stressors. Contradictory studies also reported that vitamin $C$ supplementation in heat stressed broilers reduces plasma corticosterone level and improve their physiological response (Kulkani et al., 2012). The vitamin C supplementation may result into significant decrease in serum corticosterone in heat stressed Japanese quail (Sahin et al., 2004).
The lowest Hetrophil lymphocyte $(\mathrm{HL})$ ratio was recorded in birds supplemented with turmeric. The rise in the blood $\mathrm{HL}$ ratio (as a stress indicator) is considered as an indication of overactivation of the hypothalamic-pituitary-adrenal (HPA) axis. Turmeric suppress the activity of HPA and lowers HL ratio (Schmidt et al., 2012) Similar, it was reported that turmeric supplementation decreases $\mathrm{HL}$ ratio in heat stressed broiler chicken (Hosseini et al., 2012). Moreover, betaine supplemented broilers had smaller increase in $\mathrm{HL}$ ratios $(\mathrm{HLR})$ than those in the control group during heat exposure (Zulkifli et al., 2004).

\section{Meat quality attributes}

\section{Sensory evaluation}

Betaine supplemented birds showed darker meat color while lighter color was recorded in chia seed fed birds. However, panel did not find any difference regarding breast color results of Japanese quail. In this study no difference was observed regarding the breast meat flavor and juiciness of Japanese quail supplemented with different anti-stressors. Similarly, in broilers fed with chia seed, no significant difference was observed regarding flavor in sensory evaluation (Ayerza et al., 2002). However, other studies reported that broiler chicken supplemented with turmeric resulted in improved flavor and palatability (Hosseini et al., 2012). Betaine supplemented birds showed maximum score, meaning that meat has more tenderness and oiliness whereas minimum tenderness and oiliness score was observed in birds fed with vitamin C.

In this study, panel did not find any difference regarding breast meat overall acceptability of Japanese quail reared under different anti-stressors. Similar findings also reported that in chia seed supplemented broilers, no effect was found regarding acceptance in sensory evaluation (Ayerza et al., 2002). No significant differences in taste preference or flavor were found among chia treatments in laying hens (Ayerza \& Coates, 2002). However, contradictory study found that the Japanese quail fed with vitamin $C$ in their diet resulted insignificant improvement in overall meat quality (Imik et al., 2010).

\section{Processing traits}

In this study, betaine supplemented birds showed higher redness in meat. However, no difference was observed regarding meat color lightness, yellowness, chroma and hue angle and $\mathrm{pH}$. Similar, there was no effect of vitamin $C$ or betaine supplementation on color and $\mathrm{pH}$ of meat in slow growing chicks (Attia 
Rasul M, Mehmod S, Ahmad S, Javid A,

Mahmud A, Rehman A, Usman M,

Hussain J, Ahmad M, Azhar M

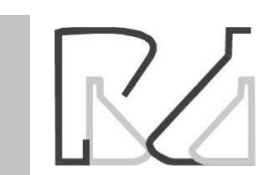

Effects of Different Anti-Stressors on Growth, Serum Chemistry and Meat Quality Attributes of Japanese Quail et al., 2009). However, contradictory studies noted that initial and ultimate $\mathrm{pH}$ values of breast and thigh meat were higher in vitamin C supplemented broilers. The $L^{*}$ value of breast and thigh meat of vitamin C supplemented broilers were significantly lower whereas $a^{*}$ value was higher when compared to the control group (Toplu et al., 2014).

\section{Anti-oxidant assay}

In the present study, lowest fat content \% was recorded in Japanese quail meat supplemented with chia seed. However, other studies reported that the chia seed supplementation causes no significant effect on fat and cholesterol content among treatments in white (breast) or dark (legs) meat of broilers (Ayerza et al., 2002).

Phenolic are aromatic benzene ring compounds with one or more hydroxyl groups (including polyphenols, Butylated hydroxytoluene, Butylated hydroxy anisole and gallic acid) that are components of plants have strong antioxidant capacity that provide protection against oxidative stress (Steinberg et al., 1989). Total phenolic contents (TPC) are measured in $\mathrm{mg} \mathrm{GAE} / \mathrm{ml}$ unit (Wang et al., 1997). The Japanese quail supplemented with betaine showed highest TPC while lowest TPC has been recorded in vitamin $C$ fed birds. Higher TPC of betaine supplemented diet over vitamin C supplemented diet fed birds might be attributed to the higher magnitude of polyphenols in betaine. Similarly, the concentration of TPC per mg GAE/ml of synthetic vitamin C in broilers was recorded lowest as compared to all other treatment groups (Sujatha et al., 2010).

Findings of the present study indicated that lowest TFC has been observed in betaine supplemented Japanese quail whereas the birds reared under control group showed highest TFC. Lower TFC in meat of betaine supplemented birds might be due to the absence of flavonoids, as flavonoids are a group of plant metabolites (including compounds such as flavones, isoflavones, flavonones, anthocyanins, and catechins) that are components of fruits and vegetables have strong antioxidant capacity (Wang et al., 1997).

Total antioxidant capacity (TAC) is a tool frequently used to assess the antioxidant status of biological samples and can evaluate the antioxidant response against the free radicals produced in stress condition. In this experiment, TAC was observed highest in betaine supplemented Japanese quail meat whereas the lowest TAC was recorded in control group birds. Another study reported that the TAC of synthetic vitamin $C$ in broilers was lower than other treatment groups (Sujatha et al., 2010).

\section{Economics}

The birds reared under betaine were more economical as compared to the rest of the treatments. This might be due to the higher weight gain of betaine supplemented birds and relatively lower cost of betaine (Table 3).

\section{CONCLUSIONS}

In conclusion, betaine being the most economical anti-stressor, it can be used in diet of growing Japanese quail during humid and hot season, having no detrimental effect on bird's performance.

\section{CONFLICT OF INTEREST DECLARATION}

No potential conflict of interest is indicated by the authors.

Table 1 - Composition of experimental ration offered during brooding and rearing phase(0-4 week).

\begin{tabular}{|c|c|c|c|c|c|}
\hline Ingredients & Control & Betaine & Vitamin C & Turmeric & Chia seed \\
\hline Anti-stressor mg / Kg & -- & 700 & 600 & 300 & 7000 \\
\hline Corn & 57.21 & 57.21 & 57.21 & 57.21 & 57.21 \\
\hline Sunflower Meal 26\% & 6.44 & 6.44 & 6.44 & 6.44 & 6.44 \\
\hline Soy oil & 2 & 2 & 2 & 2 & 2 \\
\hline Soya bean meal $45 \%$ & 29.88 & 29.88 & 29.88 & 29.88 & 29.88 \\
\hline Lime stone & 1.16 & 1.16 & 1.16 & 1.16 & 1.16 \\
\hline MDCP & 1.73 & 1.73 & 1.73 & 1.73 & 1.73 \\
\hline Salt & 0.38 & 0.38 & 0.38 & 0.38 & 0.38 \\
\hline Supplement & 0.2 & 0.2 & 0.2 & 0.2 & 0.2 \\
\hline All-met & 0.27 & 0.27 & 0.27 & 0.27 & 0.27 \\
\hline Threonine & 0.12 & 0.12 & 0.12 & 0.12 & 0.12 \\
\hline Lysine sulphate & 0.12 & 0.12 & 0.12 & 0.12 & 0.12 \\
\hline Choline chloride & 0.025 & 0.025 & 0.025 & 0.025 & 0.025 \\
\hline Crude protein \% & 20 & 20 & 20 & 20 & 20 \\
\hline M.E kcal/kg & 2900 & 2900 & 2900 & 2900 & 2900 \\
\hline
\end{tabular}


Rasul M, Mehmod S, Ahmad S, Javid A.

Mahmud A, Rehman A, Usman M,

Hussain J, Ahmad M, Azhar M
Effects of Different Anti-Stressors on Growth, Serum Chemistry and Meat Quality Attributes of Japanese Quail

Table 2 - Effect of different anti-stressors on growth performance (4 weeks) of Japanese quail.

\begin{tabular}{|c|c|c|c|c|c|c|}
\hline Parameters & Control & Betaine & Vitamin C & Turmeric & Chia seed & $p$-value \\
\hline $\mathrm{Fl}(\mathrm{g})$ & $446.48 \pm 12.33^{a}$ & $381.10 \pm 3.48^{b}$ & $473.94 \pm 16.98^{a}$ & $435.85 \pm 19.91^{a}$ & $429.78 \pm 11.61^{a}$ & 0.0029 \\
\hline TG $(g)$ & $155.68 \pm 2.05^{b}$ & $178.98 \pm 3.71^{\mathrm{a}}$ & $176.88 \pm 2.61^{a}$ & $156.23 \pm 1.77^{b}$ & $157.31 \pm 4.43^{b}$ & 0.0001 \\
\hline TOG & $20.15 \pm 0.31^{b}$ & $22.47 \pm 0.40^{a}$ & $22.67 \pm 0.28^{a}$ & $20.11 \pm 0.27^{b}$ & $20.11 \pm 0.43^{b}$ & 0.0001 \\
\hline FCR & $2.87 \pm 0.06^{\mathrm{a}}$ & $2.13 \pm 0.04^{b}$ & $2.68 \pm 0.11^{\mathrm{a}}$ & $2.79 \pm 0.12^{\mathrm{a}}$ & $2.74 \pm 0.06^{a}$ & 0.0001 \\
\hline LIV \% & $83.20 \pm 3.64$ & $88.00 \pm 1.69$ & $86.13 \pm 3.00$ & $88.80 \pm 1.91$ & $85.87 \pm 3.00$ & 0.6439 \\
\hline
\end{tabular}

Superscripts on different means within row exhibit significant difference $(p \leq 0.0 .5)$; Fl: feed intake; TG: total gain; TOG: times of gain; FCR: feed conversion ratio; Liv: livability \%.

Table 3 - Economics of quail production reared under different anti-stressors.

\begin{tabular}{lccccc}
\hline Parameters & Vitamin C & Betaine & Turmeric & Chia Seeds & Control \\
\hline Feed consumed (g) & 473.94 & 381.10 & 435.85 & 429.78 & 446.48 \\
Cost of day old chick (\$) & 0.069 & 0.069 & 0.069 & 0.069 & 0.069 \\
Total feed cost (\$) & 0.19 & 0.15 & 0.17 & 0.17 & 0.17 \\
Miscellaneous cost $(\$)$ & 0.087 & 0.087 & 0.087 & 0.087 & 0.087 \\
Anti-stressors cost/ feed intake (\$) & 0.0027 & 0.00062 & 0.00023 & 0.016 & 0.000 \\
Total cost/quail (\$) & 0.34 & 0.31 & 0.33 & 0.34 & 0.33 \\
Total live weight/quail (\$) & 1.60 & 1.62 & 1.42 & 1.43 & 1.42 \\
Sale price/ Kg live weight (\$) & 2.25 & 2.25 & 2.25 & 2.25 & 2.25 \\
Total sale price / quail (\$) & 0.42 & 0.42 & 0.37 & 0.37 & 0.37 \\
Net Profit/ quail (\$) & 0.073 & 0.12 & 0.043 & 0.033 & 0.038 \\
Profit / quail $(\%)$ & 21.09 & 38.08 & 13.27 & 9.74 & 11.55 \\
\hline
\end{tabular}

Table 4 - Effect of different anti-stressors on slaughter characteristics of Japanese quail.

\begin{tabular}{|c|c|c|c|c|c|c|}
\hline Parameters & Control & Betaine & Vitamin C & Turmeric & Chia seed & $p$-value \\
\hline $\operatorname{LW}(g)$ & $170.60 \pm 3.39$ & $177.40 \pm 6.14$ & $181.80 \pm 9.43$ & $178.60 \pm 6.83$ & $177.60 \pm 4.51$ & 0.8010 \\
\hline DW (g) & $97.20 \pm 2.82$ & $101.80 \pm 2.42$ & $104.20 \pm 5.51$ & $101.00 \pm 4.36$ & $102.80 \pm 3.06$ & 0.7509 \\
\hline Dressing \% & $56.94 \pm 0.75$ & $57.52 \pm 1.40$ & $57.32 \pm 0.58$ & $56.51 \pm 0.53$ & $57.86 \pm 0.29$ & 0.7899 \\
\hline SW \% & $2.59 \pm 0.18$ & $2.60 \pm 0.13$ & $2.44 \pm 0.14$ & $2.46 \pm 0.09$ & $2.59 \pm 0.11$ & 0.8343 \\
\hline HW \% & $3.63 \pm 0.17$ & $4.05 \pm 0.13$ & $4.00 \pm 0.20$ & $3.80 \pm 0.12$ & $4.18 \pm 0.17$ & 0.1733 \\
\hline Liver \% & $2.35 \pm 0.27$ & $2.49 \pm 0.16$ & $2.34 \pm 0.23$ & $2.36 \pm 0.11$ & $2.48 \pm 0.23$ & 0.9670 \\
\hline Gizzard \% & $3.50 \pm 0.37$ & $3.24 \pm 0.24$ & $3.32 \pm 0.24$ & $3.68 \pm 0.21$ & $3.71 \pm 0.14$ & 0.6066 \\
\hline Heart \% & $0.71 \pm 0.12$ & $1.12 \pm 0.17$ & $0.98 \pm 0.08$ & $1.01 \pm 0.20$ & $0.79 \pm 0.14$ & 0.3034 \\
\hline Drumstick \% & $6.92 \pm 0.37^{a}$ & $6.55 \pm 0.12^{\mathrm{ab}}$ & $5.96 \pm 0.37^{b}$ & $5.71 \pm 0.22^{b}$ & $6.31 \pm 0.09^{a b}$ & 0.0344 \\
\hline Thigh \% & $8.44 \pm 0.27$ & $8.37 \pm 0.23$ & $9.00 \pm 0.17$ & $8.73 \pm 0.40$ & $8.99 \pm 0.30$ & 0.3832 \\
\hline
\end{tabular}

Superscripts on different means within row exhibit significant difference ( $p \leq 0.05)$; LW: Live weight; DW: Dressed weight; SW: Shank weight; HW: Head weight.

Table 5 - Effect of different anti-stressors on meat quality attributes of Japanese quail.

\begin{tabular}{|c|c|c|c|c|c|c|}
\hline Parameters & Control & Betaine & Vitamin C & Turmeric & Chia seed & $p$-value \\
\hline$L^{*}$ & $47.10 \pm 1.18$ & $45.31 \pm 0.64$ & $46.09 \pm 1.12$ & $47.02 \pm 1.37$ & $44.34 \pm 0.65$ & 0.3095 \\
\hline$a^{*}$ & $16.89 \pm 0.63$ & $15.90 \pm 0.74$ & $17.77 \pm 0.48$ & $17.43 \pm 0.28$ & $17.11 \pm 0.53$ & 0.2046 \\
\hline$b^{*}$ & $9.97 \pm 0.69$ & $8.55 \pm 0.22$ & $9.18 \pm 0.55$ & $9.97 \pm 0.68$ & $8.53 \pm 0.51$ & 0.1973 \\
\hline$C$ & $19.64 \pm 0.84$ & $17.94 \pm 0.77$ & $20.01 \pm 0.64$ & $20.00 \pm 0.52$ & $19.13 \pm 0.66$ & 0.2281 \\
\hline$h^{\circ}$ & $29.33 \pm 2.18$ & $26.73 \pm 1.14$ & $27.22 \pm 0.98$ & $29.82 \pm 1.49$ & $26.42 \pm 0.95$ & 0.3404 \\
\hline pH-ultimate & $5.70 \pm 0.08$ & $5.71 \pm 0.06$ & $5.66 \pm 0.03$ & $5.73 \pm 0.03$ & $5.60 \pm 0.02$ & 0.3923 \\
\hline \multicolumn{7}{|c|}{ Sensory Evaluation } \\
\hline Color & $7.07 \pm 0.16$ & $7.37 \pm 0.20$ & $6.90 \pm 0.28$ & $7.17 \pm 0.21$ & $6.83 \pm 0.16$ & 0.3755 \\
\hline Flavor & $6.30 \pm 0.24$ & $6.87 \pm 0.16$ & $6.37 \pm 0.24$ & $6.77 \pm 0.21$ & $6.47 \pm 0.19$ & 0.2252 \\
\hline Juiciness & $6.53 \pm 0.27$ & $7.30 \pm 0.20$ & $6.58 \pm 0.28$ & $6.83 \pm 0.16$ & $6.55 \pm 0.23$ & 0.0973 \\
\hline Tenderness & $6.43 \pm 0.24^{b}$ & $7.37 \pm 0.22^{\mathrm{a}}$ & $6.37 \pm 0.28^{b}$ & $6.87 \pm 0.21^{\mathrm{ab}}$ & $6.48 \pm 0.16^{b}$ & 0.0100 \\
\hline Oiliness & $5.87 \pm 0.26^{b}$ & $6.67 \pm 0.19^{a}$ & $5.77 \pm 0.23^{b}$ & $6.13 \pm 0.16^{\mathrm{ab}}$ & $5.95 \pm 0.21^{b}$ & 0.0285 \\
\hline Acceptability & $6.70 \pm 0.23$ & $7.10 \pm 0.17$ & $9.00 \pm 2.29$ & $6.63 \pm 0.25$ & $6.80 \pm 0.18$ & 0.4566 \\
\hline
\end{tabular}

Superscripts on different means within row exhibit significant difference $(p \leq 0.05)$; $L^{*}$ : Lightness, $a^{*}$ : Redness, $b^{*}$ : Yellowness, c: Chroma, h: Hue angle. 
Rasul M, Mehmod S, Ahmad S, Javid A, Mahmud A, Rehman A, Usman M, Hussain J, Ahmad M, Azhar M
Effects of Different Anti-Stressors on Growth, Serum Chemistry and Meat Quality Attributes of Japanese Quail

Table 6 - Effect of different anti-stressors on meat antioxidant assay and serum chemistry of Japanese quail.

\begin{tabular}{lcccccccc}
\hline Treatment & $\begin{array}{c}\text { Fat } \\
\%\end{array}$ & $\begin{array}{c}\text { TPC } \\
\mathrm{mg} \mathrm{GAE} / \mathrm{ml}\end{array}$ & $\begin{array}{c}\mathrm{TFC} \\
\mathrm{mg} \mathrm{RE} / \mathrm{ml}\end{array}$ & $\begin{array}{c}\text { TAC } \\
\mathrm{mg} \mathrm{AAE} / \mathrm{ml}\end{array}$ & $\begin{array}{c}\text { Cortisol } \\
(\mu \mathrm{g} / \mathrm{dl})\end{array}$ & $\begin{array}{c}\text { Glucose } \\
(\mathrm{mg} / \mathrm{dl})\end{array}$ & $\begin{array}{c}\text { Cholesterol } \\
(\mathrm{mg} / \mathrm{dl})\end{array}$ \\
Control & 1.32 & 62.25 & 268.562 & 82.11 & $0.12 \pm 0.06$ & $200.26 \pm 14.72^{\mathrm{a}}$ & $\begin{array}{c}\mathrm{H}: \mathrm{L} \\
276.40 \pm 41.27^{\mathrm{a}}\end{array}$ & $0.61 \pm 0.13^{\mathrm{a}}$ \\
\hline Betaine & 1.12 & 63.48 & 103.735 & 154.712 & $0.06 \pm 0.01$ & $142.64 \pm 11.17^{\mathrm{b}}$ & $148.20 \pm 13.41^{\mathrm{b}}$ & $0.60 \pm 0.11^{\mathrm{a}}$ \\
Vitamin C & 1.46 & 60.11 & 145.195 & 138.638 & $0.04 \pm 0.01$ & $195.70 \pm 10.81^{\mathrm{a}}$ & $263.20 \pm 34.18^{\mathrm{a}}$ & $0.51 \pm 0.07^{\mathrm{a}}$ \\
\hline Turmeric & 1.34 & 63.33 & 160.677 & 116.33 & $0.05 \pm 0.02$ & $196.05 \pm 6.68^{\mathrm{a}}$ & $198.60 \pm 29.89^{\mathrm{ab}}$ & $0.21 \pm 0.05^{\mathrm{b}}$ \\
Chia seed & 0.93 & 63.51 & 157.42 & 107.52 & $0.09 \pm 0.02$ & $158.68 \pm 5.00^{\mathrm{b}}$ & $200.00 \pm 23.09^{\mathrm{ab}}$ & $0.68 \pm 0.06^{\mathrm{a}}$ \\
\hline$p$-value & & & & & 0.3449 & 0.0016 & 0.0397 & 0.0133 \\
\hline
\end{tabular}

Superscripts on different mean within column show significant difference $(p \leq 0.05)$; TPC: total phenolic content, TFC: total flavonoid content, TAC: total antioxidant capacity, HL: heterophil lymphocyte ratio.

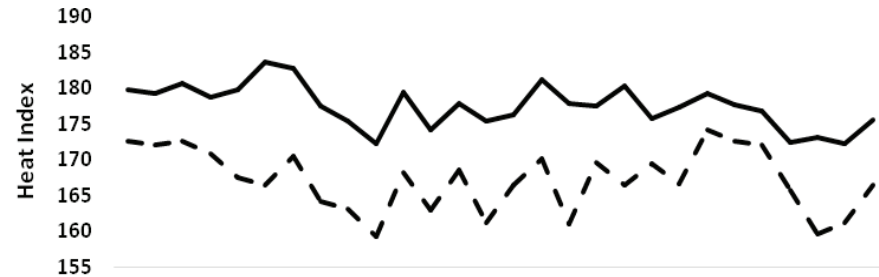

1223445567789910111213141516171819202122232425262728 Day

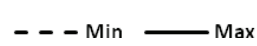

Figure 1 - Daily trend of Heat Index during experimental period

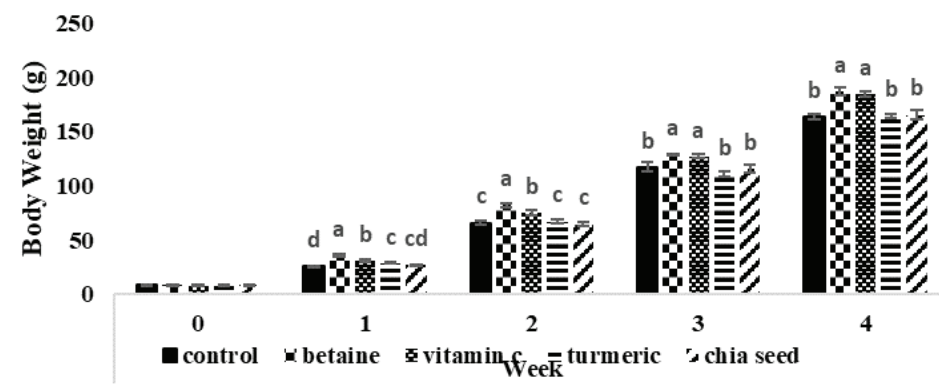

Figure $\mathbf{2}$ - Trend of weekly body weight of Japanese quail reared under different anti-stressors.

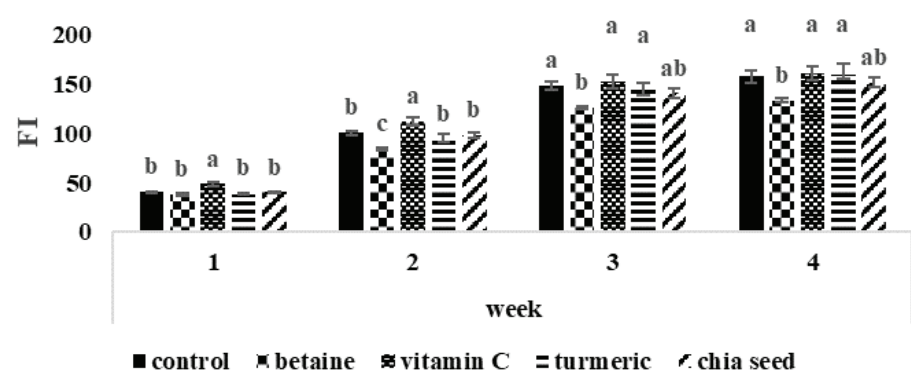

Figure 3 - Trend of weekly feed intake of Japanese quail reared under different anti-stressors.

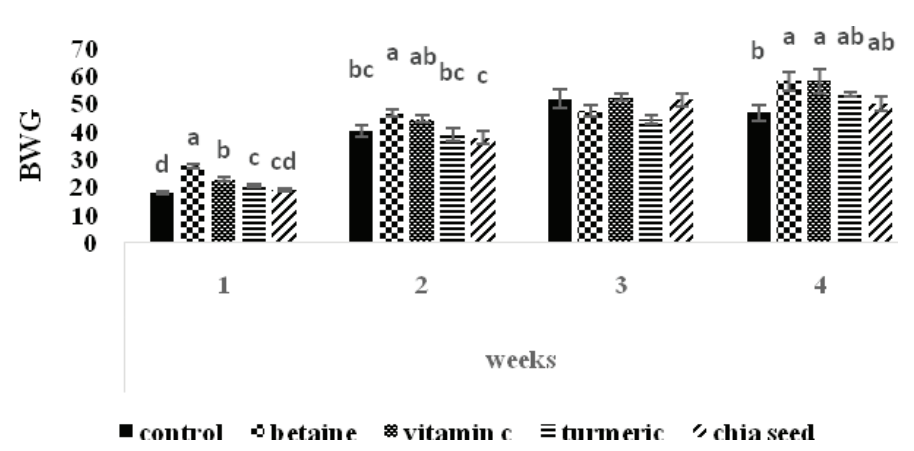

Figure 4 - Trend of weekly body weight gain of Japanese quail reared under different anti-stressors.

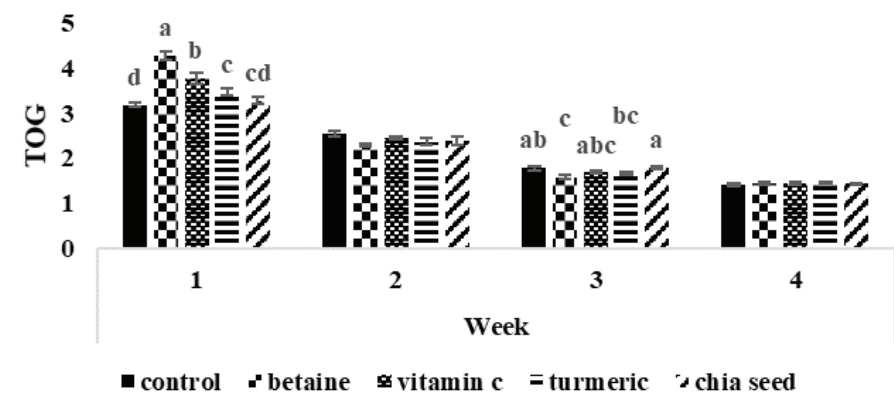

Figure $\mathbf{5}$ - Trend of weekly times of gain of Japanese quail reared under different anti-stressors.

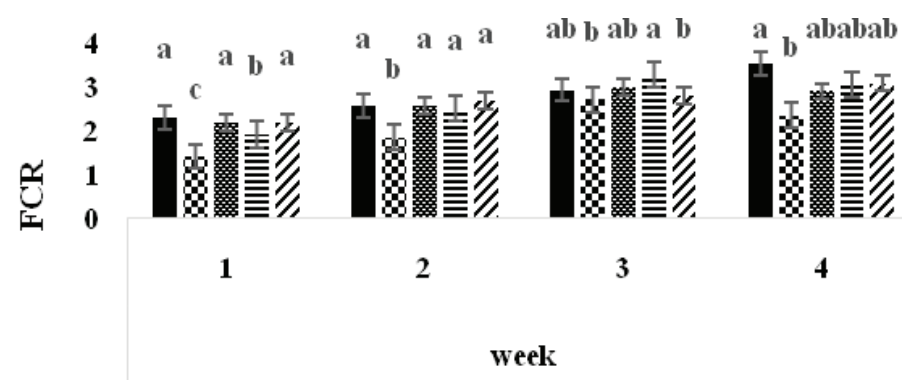

Econtrol obetaine vitamin C Etmrmeric " chia seed

Figure 6 - Trend of weekly feed conversion ratio of Japanese quail reared under different anti-stressors. 
Rasul M, Mehmod S, Ahmad S, Javid A,

Mahmud A, Rehman A, Usman M,

Hussain J, Ahmad M, Azhar M

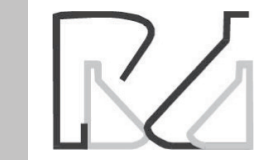

Effects of Different Anti-Stressors on Growth, Serum Chemistry and Meat Quality Attributes of Japanese Quail

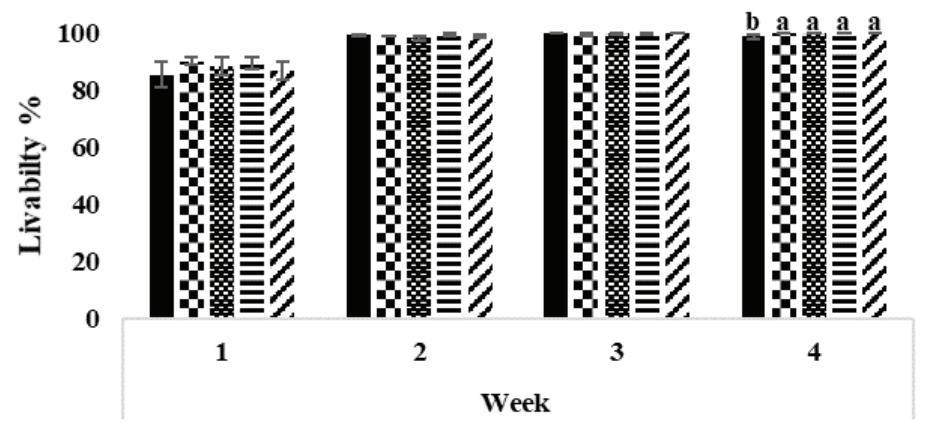

a Control Betaine $\$$ Vitamin $\mathrm{C}=$ Termeric $\approx$ Chia seed

Figure 7 - Trend of weekly livability of Japanese quail eared under different anti-stressors.

\section{REFERENCES}

Adibmoradi M, Navidshad B, Seifdavati J, Royan M. Effect of dietary garlic meal on histological structure of small intestine in broiler chickens. Poultry Science 2006;43:378-383.

Ahmad S. Quail farming: an industry overview. Pakistan Poultry MAG 2016:6(22):17-18.

Akram M. Over 2,500 Punjab poultry farms closed in two years. Lahore: The Nation; 2013. p. 9

AOAC - Association of Official Analytical Chemists. Official methods of analysis. $15^{\text {th }}$ ed. Arlington; 1990.

Attia YA, Hassan RA, Qota MA. Recovery from adverse effects of heat stress on slow-growing chicks in tropics 1 :effect of ascorbic acid and different levels of betain. Tropical Animal Health Production 2009;41:807-818.

Attia YA, Hassan RA, Shehatta MH, Abd El-hady SB. Growth, carcass quality and blood serum constituents of slow growth chicks as affected by betain additions to diets containing different levels of methionine. International Journal of Poultry Science 2005;11:856-865.

Ayerza R, Coates W. Dietary levels of chia: influence on hen weight, egg production, and egg sensory quality, for two strains of hens. British Poultry Science 2002;43(2):283-290

Ayerza R, Coates W, Lauria M. Chia seed (Salvia hispanica L.) as an $\omega$-3 fatty acid source for broilers: influence on fatty acid composition, cholesterol and fat content of white and dark meats, growth performance, and sensory characteristics. Poultry Science 2002;81:826-837.

Bello AU, Sulaiman JA. Stress response in Japanese quails (Coturnix coturnix japonica) to physiological alzet-osmotic pumps. Journal of Natural Science, Biology and Medicine 2016;5(2):85-92.

Borges SA, Fischer AV, Silva DA, Maiorka A. Acid base balance in broilers. World's Poultry Science Journal 2007;63:73-81.

Castellini C, Mugnai C, Dal BA. Effect of organic production system on broiler carcass and meat quality. Meat Science 2002;60:219-225.

Chen $\mathrm{H}$, Chiang S. Effect of dietary betaine supplementation on the heat tolerance in broilers. Marlborough: Danisco Animal Nutrition Wiltshire; 2002

Daghir NJ. Poultry production in hot climates. $2^{\text {nd }}$ ed. Wallingford: $C A B I$ International; 2008.

Daghir NJ. Nutritional strategies to reduce heat stress in broilers and broiler breeders. Lohmann Information 2009;44:6-15.
Duncan DB. Multiple range and multiple F tests. Biometrics 1955;11:1-42.

El-Deek, Mervat S, El-Deen L, Safaa M, Hamdy MA, Asar HM, et al. Effect of different dietary levels of $\mathrm{NaCl}$ and $\mathrm{KCl}$ on performance of broiler chicks fed plant diets. Egyptian Poultry Science 2009;29(4):907-921.

Enting $H$, Eissen J. Role of betaine in preventing heat stress. Feed Mix 2007;15:25-26

Gill A, Delaquis P, Russo P, Holley R. Evaluation of antilistreial action of cilantro oil on vacuum packed ham. International Journal of Food Microbiology 2002;73:83-92.

Graham $H$. Betaine-combating heat stress in poultry. AFMA Matrix 2002;15:16-17

Gross WB, Siegel HS. Evaluation of the heterophil / lymphocyte ratio as a measure of stress in chickens. Avian Diseases1983;27:972-979.

Hassan RA, Attia YA, El-Ganzory EH. Growth, carcass quality and serum constituents of slow growing chicks as affected by betaine addition to diets containing. 1. Different levels of choline. International Journal of Poultry Science 2005;4(11):840-850.

Hayat J, Balnave D, Brake J. Sodium bicarbonate and potassium bicarbonate supplements for broilers can cause poor performance at high temperatures. British Poultry Science1999;40:411-418.

Hosseini-Vashan SJ, Golian A, Yaghobfar A, Zarban A, Afzali A, Esmaeilinasab P. Antioxidant status, immune system, blood metabolites and carcass characteristic of broiler chickens fed turmeric rhizome powder under heat stress. African Journal of Biotechnology 2012;11(94).

Imik H, Atasever M, Koc M, Ozturan K. Effect of dietary supplementation of some antioxidants on growth performance, carcass composition and breast meat characteristics in quails reared under heat stress. Czech Journal of Animal Science 2010;55:209-220.

Kayang BB, Vignal AM, Inoue-Murayama M, Miwa JL, Monvoisin S, Minvielle F. A first generation micro satellite linkage map of the Japanese quail. Animal Genetics 2004;35:195-200.

Khanahmadi M, Rezazadeh SH, Taran M. In vitro antimicrobial and antioxidant properties of Smyrniumcordifoliumboiss (Umberlliferae) extract. Asian Journal of Plant Science 2010;9:99-103.

Khattak FM, Acamovic T, Sparks N, Pasha TN, Joiya MH, Hayat Z, et al. Comparative efficacy of different supplements used to reduce heat stress in broilers. Pakistan Journal of Zoology 2012;44(1):31-41.

Kidd MT, Ferket PR, Garlich JD. Nutritional and osmoregulation function of betain. World's Poultry Science Journal 1997;53:125-139.

Kulkani RC, Mandal AB, Bhanja SK, Goel A, Mehra M, Yadav AS. Role of dietary supplemental Ascorbic Acid in broiler chicken during extreme hot summer. World's Poultry Science Journal Supplement 2012;132135.

Kutlu HR, Forbes JM. Changes in growth and blood parameters in heatstressed broiler chicks in response to dietary ascorbic acid. Livestock Production Science 1993;36:335-350.

Lini H, Jiaoi HC, Buyse J, Decuypere E. Strategies for preventing heat stress in poultry. World's Poultry Science Journal 2006;62:71-86.

Mahmoud S. Effect of thermal stress on fertility and egg quality of Japanese quail. Journal of Thermal Biology 2016;61:38-43

Mehmet AVCI, Murdat Y, Oktay K. Effects of ascorbic acid on the performance and some blood parameters of japanese quails reared under hot climate conditions. Turkish Journal of Veterinary and Animal Sciences 2005;29:829-833. 
Rasul M, Mehmod S, Ahmad S, Javid A,

Mahmud A, Rehman A, Usman M,

Hussain J, Ahmad M, Azhar M
Effects of Different Anti-Stressors on Growth, Serum Chemistry and Meat Quality Attributes of Japanese Quail
Minvielle $\mathrm{F}$. The future of Japanese quail for research and production. World's Poultry Science Journal 2004;60(4):500-507.

Nabasree D, Bratati D. Antioxidant activity of some leafy vegetables of India. A Comparative Study of Food Chemistry 2007;101:471-474.

Nile SH, Khobragade CN. Antioxidant activity and flavonoid derivatives of Plumbago zeylanica. Journal of Natural Products 2010;3:130-133.

Rima O. The Metabolic burden of methyl donor deficiency with focus on the betaine homocysteine methyltransferase pathway. Nutrients 2013;5:3481-3495.

Sahin K, Kuçuk O. Effects of vitamin C and Vitamin E on performance, digestion of nutrients and carcass characteristics of Japanese quails reared under heat stress $\left(34^{\circ} \mathrm{C}\right)$. Journal of Animal Physiology and Animal Nutrition 2001;85:335-342.

SahinK, Orhan C, Tuzcu Z, Tuzcu M, Sahin N. Curcumin ameloriates heat stress via inhibition of oxidative stress and modulation of $\mathrm{Nrf2} / \mathrm{HO}-1$ pathway in quail. Food Chemistry and Toxicology 2012;50:4035-4041.

Sahin K, Sahin N, Kucuk O, Hayirlu A, Prasad AS. Role of dietary zinc in heat stressed poultry: a review. Poultry Science 2009;88:2176-2183.

Sahin K, Sahin N, Onderci M, Mehmet F, Gursu M. Vitamin C and E can alleviate negative effects of heat stress in Japanese quails. Food Agriculture Environment 2003;1(2):244-249.

Sahin N, Onderci M, Sahini K, Gursu MF, Smith MO. Ascorbic acid and melatonin reduce heat-induced performance inhibition and oxidative stress in Japanese quail. British Poultry Science Journal 2004;45(1):116122.

Saraswati TR, Manalu W, Ekastuti DR, Kusumorini N. Increased egg production of japanese quail (Cortunix japonica) by improving liver function through turmeric powder supplementation. International Journal of Poultry Science 2013;12(10):601-614.

Schmidt KL, Furlonger AA, Lapierre JM, MacDougall-Shackleton EA, MacDougall-Shackleton SA. Regulation of the HPA axis is related to song complexity and measures of phenotypic quality in song sparrows. Hormones and Behavior 2012;61:652-659.

Shahdan IA, Regenstein JM, Shahabuddin ASM, Rahman MT. Developing control points for halal slaughtering of poultry. Poultry Science 2016;95:1680-1692

Si W, Gong J, Tsao R, Zhou T, Yu H, Poppe C, et al. Antimicrobial activity of essential oils and structurally related synthetic food additives towards selected pathogenic and beneficial gut bacteria. Journal of Applied Microbiology 2006;100:296-305.
Smith MO, Teeter TG. Potassium balance of the 5 to 8-week-old broiler exposed to constant heat or cycling high temperature stress and the effects of supplemental potassium chloride on body weight gain and feed efficiency. Poultry Science 1993;66:487-492.

Steel RGD, Torrie JH, Dickie DA. Principles and procedures of statistics. A biometric approach. $3^{\text {rd }}$ ed. Toronto: McGraw-Hill Book Publishing; 1997.

Steinberg D, Parthasarathy S, Carew TE, Khoo JC, Witztum JL. Beyond cholesterol: modification of lowdensity lipoprotein that increases its atherogenicity. New England Journal of Medicine 1989;320:915-924.

Sujatha V, Korde JP, Rastogi SK, Maini S, Ravikanth K, Rekhe DS. Amelioration of heat stress induced disturbances of the antioxidant defense system in broilers. Journal of Veterinary Medicine Animal Health 2010;2(3):1828.

Surai PF, Fisinin VI. Vitagenes in poultry production, Technological and environmental stresses. World's Poultry Science Journal 2016;72:721733

Toplu HDO, Nazligul A, Karaarslan S, KayaM, Yagin O. Effects of heat conditioning and dietary ascorbic acid supplementation on growth performance, carcass and meat quality characteristics in heat-stressed broilers. Ankara Üniversitesi Veteriner Fakültesi Dergisi 2014;61:295302.

Uribe JAR, Perez JIN, Kauil HC, Rubio GR, Alcocer CG. Extraction of oil from chia seeds with supercritical $\mathrm{CO}_{2}$. Journal of Supercritical Fluids 2011:56(2):174-178

Wang H, Cao G, Prior RL. Oxygen radical absorbing capacity of anthocyanins Journal of Agriculture Food Chemistry 1997;45:304-309.

Wang $Y Z, X u Z R$, Feng $G$. The effect of betaine and dl-methionine on growth performance and carcass characteristics in meat ducks. Animal Feed Science and Technology 2004;11(6):151-159.

Whitehead CC, Keller T. An update on ascorbic acid in poultry. World's Poultry Science Journal 2003;59:161-184.

Zulkifli I, Chenorma MT, Israf DA, Omar AR. The effect of early age feed restriction on subsequent response to high environmental temperatures in female broiler chickens. Poultry Science 2000;79:1401-1407.

Zulkifli I, Mysahra SA, Jin LZ. Dietary supplementation of betaine (betafin) and response to high temperature stress in male broiler chickens. Journal of Animal Science 2004;17(2):244-249. 